\title{
FOCUS: DISASTER PREPAREDNESS IN THE BLOOD
}

\section{Disaster Preparedness in the Blood Bank}

\section{ALYSE N. GSCHWENDER, LAURIE GILLARD}

\section{LEARNING OBJECTIVES}

1. Outline and describe the disaster management cycle.

2. Identify guidelines available for developing a disaster management program.

3. List technology and methods that blood centers and hospitals use to forecast blood product need during a disaster.

\section{ABSTRACT}

When a natural or manmade disaster occurs, the first place the wounded are relocated to is the hospital. Disasters generate many types of injuries that may require the use of blood products. Blood Banks need to be prepared for a rapid influx of patients. Because of recent world events, the blood community has established guidelines to assist Blood Banks with creating successful Emergency Operations Procedures. Blood Banks can use these guidelines to create mock scenarios and tabletop exercises to estimate how the blood supply will be affected in the wake of disasters such as pandemics and blood shortages. Retrospective review of past disaster experiences such as earthquakes, airline crashes, and bombings can be used to evaluate what went well and what improvements to the process need to be made. Developing a disaster plan is a multistep process that includes determining the need for blood products, routes of communication, how to mobilize hospital staff, and how to procure more blood products. Once a plan is created, it should be practiced and improved upon, so flaws in the plan can be corrected and the best possible care for patients can be provided.

\footnotetext{
ABBREVIATIONS: CLSI - Clinical Laboratory Standards Institute, AABB - organization formerly known as the American Association of Blood Banks, ED - emergency department, EMS - emergency medical service, EOP - emergency operations plan, MRCC Medical Resource Control Center, MCI - Mass Casualty Incident, TASMC - Tel Aviv Sourasky Medical Center, MAC - Medical Alert Center
}

INDEX TERMS: Disaster Management, Blood Banks, Emergency Operations Procedures, Massive Transfusion

Clin Lab Sci 2017;30(4):250

Alyse N. Gschwender, MLS (ASCP) ${ }^{\mathrm{CM}}$, SBB (ASCP) $^{\mathrm{CM}}$, Saint Clair Shores, MI

Laurie Gillard, MS, MLS(ASCP) ${ }^{C M} S B B$, Rush University, Chicago, IL

Address for Correspondence: Laurie Gillard, MS, $M L S(A S C P)^{C M} S B B$, Director of the Specialist in Blood Banking Certificate Program, Rush University, Chicago, IL 60612

\section{INTRODUCTION}

In today's world, it is imperative to be prepared for the worst possible situations. Events like natural disasters, pandemics, terrorist attacks, building fires, and power outages affect large amounts of people and usually require the help of a hospital Blood Bank. The United Nations International Strategy for Disaster Reduction defines a disaster as "a serious event that disrupts the normal functioning of a community or society and that exceeds the affected area's ability to cope." ${ }^{1}$ Disasters can bring about chaotic and unusual scenarios that are not typically encountered in the everyday world or workplace. Without proper preparation and planning, situations can become hazardous. In order to be prepared for when a disaster strikes, there must be an understanding of the elements of a disaster plan. Hypothetical scenarios and previous disasters need to be analyzed and adapted to the institution creating the plan. Then, a plan needs to be created, approved, and practiced. ${ }^{1}$

Disasters can be classified in two ways: natural disasters, such as hurricanes and pandemics, or disasters caused by human activities, like terrorist attacks or nuclear events. Both types of events can pose different dangers to the area being affected and prompt the need for a diverse 


\section{FOCUS: DISASTER PREPAREDNESS IN THE BLOOD BANK}

appropriate response. ${ }^{1}$ Disaster management is a cycle and includes four main areas. The first area is mitigation, which focuses on altering the physical workplace in order to make it structurally sound and secure. The second area of the cycle is preparedness and entails creation of a risk analysis for potential hazards, then creation of plans and processes that are tested by those most likely to be affected by the potential hazard. Third is the response, which involves the reaction of the staff to the protection of lives and property. Fourth, is recovery and occurs after the initial response to the event. The recovery period is used to better prepare for future disasters. ${ }^{1}$ Each of these disaster management cycle areas contain intricate details that need to be considered when planning. Some emergency plans can cover more than one type of disaster or facility, while others will need to be specific to a site and/or a type of disaster. ${ }^{1}$ This article will mainly illustrate how mitigation, preparedness, response, and recovery are interweaved in disaster management.

\section{Agencies Supporting Disaster Management Guidelines}

Due to international and local disasters that have occurred over the past few decades, government agencies, law enforcement, hospital accrediting agencies, and laboratory accrediting agencies have recognized the need and accepted the task of creating guidelines in order to prepare employees and protect the public in the wake of a disaster. ${ }^{2}$ The Clinical Laboratory Standards Institute (CLSI) and the AABB (formerly known as the American Association of Blood Banks) have compiled information and created guidelines concerning the preparation for numerous disaster scenarios. ${ }^{2,3}$ When dealing with disaster management, it is imperative that the lab follows all accrediting and regulatory guidelines. The Joint Commission, which accredits health care organizations, has released Emergency Management Standards. These standards cover areas of emergency management including communications, resources and assets, safety and security, staff responsibilities, utilities and clinical services, and patient clinical support activities. However, while these standards need to be followed, specifics for the laboratory are not discussed. ${ }^{3}$ The hospital as a whole may implement the proper Emergency Operating Procedures without involving the laboratory in the planning phases. The laboratory must then decipher how these standards apply to laboratory operations. ${ }^{3}$

To aid the transfusion services to better prepare for disaster, the $\mathrm{AABB}$ has created a Disaster Operations
Handbook. By using a multidisciplinary task force to generate this handbook, the $\mathrm{AABB}$ provides guidance to blood centers and transfusion services in order to prepare for when disaster strikes and blood products are needed. ${ }^{2}$ According to the task force, "The single greatest risk of domestic disaster and acts of terrorism is not the lack of supply but disruption of the blood distribution systems." ${ }^{2}$ In order to address this and other pertinent issues, the $\mathrm{AABB}$ task force used previous disasters to highlight the most important lessons learned. From these lessons, the blood community has ascertained that blood collectors and hospitals need to maintain a seven day supply of blood and control excess blood collections in the wake of a disaster. To avoid over collection, it is also critical to communicate to the public and blood community about the status of the blood supply. Consistently planning for disasters and conducting drills, including how transportation services communicate so that blood can be transported to the area in need in the wake of a disaster is critical. ${ }^{2}$ To be prepared and to execute successful disaster management plans, a facility must consider the above points when generating plans with each department and agency.

\section{Predictive Modeling for Disaster Management}

Due to the lack of publications covering disaster planning studies, blood centers and hospitals use mock scenarios, computer simulations, and tabletop exercises to better predict what blood products may be required during a short or long-term disaster scenario. By using computer modeling, transfusion services can not only help understand the quantity of blood provisions that may be necessary during a disaster, but test prospective approaches as to how to meet the blood needs. ${ }^{4}$

\section{Pandemic Modeling}

Pandemic diseases result in a prolonged disruption of all stages of the blood supply chain from blood donations to a reduction in the number of workers performing the rest of the donation process. ${ }^{5}$ To address this issue, the state of Victoria, Australia created a mathematical model that assessed how the state blood supply would be affected during a pandemic and if transfusion restriction policies could alleviate the stress of a pandemic on the blood supply. The model was based on a retrospective study (between July 2003 and July 2008) that categorized patients based on those who had received a transfusion and then on how urgently blood was needed. Each urgency category was then subdivided into groups based 


\section{FOCUS: DISASTER PREPAREDNESS IN THE BLOOD BANK}

on those who had similar blood demands i.e. oncology patients, cardiac patients, traumas. ${ }^{5}$ Fifteen clinicians from various specialties were asked to determine probability outcomes for each patient based on what could have happened had each transfusion been postponed for various amounts of time..$^{5}$ A twenty-one day period was chosen to evaluate the affects of postponing transfusions as well as elective surgeries. The model predicted what could have potentially happened to each patient had their transfusion been postponed. By using qualified persons with experience in dealing with each patient's health concern, the credibility of prediction was strengthened. ${ }^{5}$ It was determined that those who have ineffective erythropoiesis or bone marrow failure would likely need transfusion support regardless of delaying the transfusion, which would not save units for the blood supply. Overall, these methods reduced blood usage by ten percent. ${ }^{5}$

Research in Germany has used computer simulations to determine the affects of an influenza pandemic on the blood supply. The goal of the study was to see how much of the blood inventory could be reduced and what shortage estimates would show in comparison to actual demand. It was estimated that those infected with influenza were infectious for about 3.3 days and would take about 5 days to fully recover. Those who had been sick would be deferred from donation for fourteen days. ${ }^{6}$ If, during an influenza pandemic, the donor pool was decreased, but red cell units continued to be transfused, the red cell inventory would decline and transfusions would need to be withheld. Even when withholding transfusions, a deficit of red cell units would occur within a few weeks.

Using the estimates of this study, it was determined that if minimal stock is available to help with the blood deficit during a pandemic and there was no system in place to prioritize blood usage, an even larger deficit would occur. ${ }^{6}$ Due to illness, both the number of donors and the number of staff members who could collect blood would decrease due to being infected or the need to take care of ill relatives. ${ }^{6}$ Inadequate numbers of staff would become unable to collect units, which would result in the continuous growth of the deficit in the blood supply.

Under normal situations, blood usage is more flexible and can be more readily redistributed to those with a higher need priority. In the midst of a pandemic, this may not be the case; however, not all transfusions can be postponed. In order to better cope with the depleted blood supply, this study suggests that German authorities could relax some of the criteria and regulations to donate blood so that inventory can be replenished. ${ }^{6}$ In doing this, more units will be readily available for those needing transfusion.

In order to properly prepare for a pandemic, a plan to prioritize transfusion and the release of blood from blood centers should be put in place and utilized before critical shortages occur. A database should be established to illustrate a more accurate availability and distribution of the blood supply. ${ }^{6}$ By creating these plans and estimates, precious blood stores may be more easily preserved during the potential shortcomings seen during an influenza pandemic. ${ }^{6}$

\section{Inappropriate Transfusion Modeling}

Another scenario to consider for management of the blood supply is inappropriate blood transfusions; if inappropriate transfusions are prevented, blood usage can be reduced. ${ }^{5}$ In a trauma, blood is utilized in a more rapid pace than in routine transfusions, but blood donations and the redistribution of inventory may lead to the proper inventory levels. ${ }^{5}$ By using past data, creating transfusion restriction guidelines, and triaging patient transfusions, each hospital can better estimate what their blood needs may be in certain disaster scenarios. Based on the findings, the simulations can be manipulated and policies can be put into place. While no disaster is exactly the same, having a triage system in place can help determine blood needs. ${ }^{5}$

In 2004, the Chief Medical Officer's National Blood Transfusion Committee for England and North Wales published guidelines for how hospitals should create plans for dealing with a shortage of red cells. A tabletop exercise was conducted to test this guidance and a decision of what all was involved in the "red phase" (insufficient blood inventory) of a blood shortage. A twenty-one-day period during 2006-2007 was used to review used transfusion triggers, electronic selection and issuing of blood, and intra- and post-operative blood salvage to potentially reduce the use of red blood cells. ${ }^{7}$ A transfusion team made up of a hematologist, transfusion practitioners, and a senior transfusion laboratory technician was assembled to evaluate whether or not a transfusion would be warranted for each patient 


\section{FOCUS: DISASTER PREPAREDNESS IN THE BLOOD BANK}

over the twenty-one-day period. Those in trauma situations, any emergency, cancer curing surgery, patients receiving stem cell transplants, chemotherapy patients, and patients with life threatening anemia would still receive transfusions based on the issued guidelines. An $80 \mathrm{~g} / \mathrm{L}(8.0 \mathrm{~g} / \mathrm{dL})$ hemoglobin level was established to guide transfusion indications for those with bone marrow failure or chronic renal failure. Elective surgeries like major spinal surgery, major vascular surgery, and radical prostatectomies were cancelled due to the likelihood of transfusion. Any non-surgical and non-life threatening anemia cases were deferred for transfusion as well. An estimate of blood inventory consisting of forty percent of the normal hospital blood supply and forty percent of the normal daily supply from the blood center would be used to replenish the hospital's stock to forty percent of normal. This assumption was based on published guidelines.

In using these transfusion requirements and inventory estimates, the efficiency of reducing transfusions during a blood shortage was analyzed. and 22 elective surgeries were hypothetically cancelled. Retrospective review showed that few of these patients had actually been transfused at the time of surgery. Significantly, three non-surgical patients with non-life-threatening anemia were identified as being inappropriately transfused, which would have wasted precious resources. ${ }^{7}$ Without the hypothetical stock restrictions, the "end-of-daystocks" would have been exhausted. Furthermore, it was determined that for those patients who were deferred from transfusion anywhere from two days to one week, it would have been too difficult to reschedule the transfusion of each patient. Because of this difficulty, it was decided that if a transfusion was deferred, it should be deferred for no more than twenty-four hours after the end-of-day stock numbers were completed. ${ }^{7}$

Conclusions drawn from this exercise demonstrate that the proposed guidelines would be effective during a red cell shortage. Proactively, employing sensible transfusion triggers and the use of a consultant hematologist encourages responsible transfusion practice. ${ }^{7}$ This study recommends performing these scenarios at a regional level and using potentially lower stock levels of red blood cells to try and predict what could happen. By examining the effectiveness of national guidelines and creating a tabletop exercise, viable salvage and procedural options can be determined to best fit a predicted red blood cell shortage.

\section{Using Risk Assessment to Create Plans}

The team creating a disaster plan should research published guidelines, previous data published about planning and disasters, and look at how other facilities have improved upon their plans. CLSI published "Planning for Laboratory Operations During a Disaster; Approved Guideline" in 2014. According to CLSI, this document will help the laboratory to "develop, implement, and sustain effective emergency operation plans" throughout various types of hazards and assist laboratory operations. ${ }^{3}$ This document does not give a specific layout of an Emergency Operation Plan (EOP), but it does assist with emphasizing which areas to address in the plan. Disaster planning requires various resources such as time, staff, and money. There are federal and state funding grants and contracts available to hospitals to help assist with planning expenses. ${ }^{3}$ Prior to developing specific plans, it is essential for a facility to perform a risk assessment. A risk assessment ranks the likelihood of all identified hazards a facility may encounter and these hazards should include in their EOP. ${ }^{2}$ Once the risks are determined, the emergency planning team can begin creating the EOP, which should contain the "purpose, policy, scope, terminology, mitigations, preparedness, response, and recovery plans." ${ }^{3}$

Any shortcomings in disaster planning cannot be reviewed in-depth until after a disaster strikes. The blood community can learn from past publications and the experiences of other transfusion services and blood centers that have encountered both natural and manmade disasters. ${ }^{3}$ The following scenarios show how important it is for a laboratory to have a disaster plan in place.

\section{Japan}

On March 11, 2011, the Great East Japan Earthquake occurred with a magnitude of 9.0. The ensuing tsunami killed almost 16,000 people. The Fukushima Daiichi nuclear power plant was damaged causing landslides, damaged rail lines and roads, and a flooded airport. ${ }^{8}$ This event caused a major disruption to travel, rescue, and the transport of aide. Due to the size of the tsunami, very little nonfatal trauma occurred, so the demand for transfusion did not increase. ${ }^{8}$

The Miyagi Red Cross Blood Center was affected by 


\section{FOCUS: DISASTER PREPAREDNESS IN THE BLOOD BANK}

broken water sprinklers in the ceiling, toppled equipment, and instruments that tested for infectious disease were damaged, rendering the blood center unusable. This blood center was the closest to the disaster area, so relief from other blood centers was provided. ${ }^{8}$ The hospitals that were chosen to take care of patients either did not routinely store red blood cells or did not stock very many. The earthquake also damaged the municipal water lines in Fukushima, which forced hospitals to cut down on water usage by modifying laboratory tests to use less water, using hand sanitizer, and setting up restrooms outside of the hospital. Resources were conserved and non-essential functions were postponed including elective surgeries. ${ }^{8}$

Japan's healthcare providers follow Emergency Preparedness acts and blood supply laws. The Japanese Red Cross is assisted by local governments when the transport of blood products through damaged areas is necessary and created Risk Management Guidelines for different disaster scenarios. ${ }^{8}$ While this disaster did not have very many traumatic injuries, through proper planning and coordination, the blood centers, hospitals, and others involved were able to adequately respond to the need of blood products while surpassing the geographical consequences of the earthquake. The challenges that were faced could have had a negative outcome if it had not been for the plans focusing on more than just the physical blood supply, but also the other obstacles that can be created by a natural disaster. ${ }^{8}$

\section{Minneapolis, Minnesota}

On August 1, 2007, Minneapolis, Minnesota experienced the collapse of a man-made bridge over the Mississippi River during increased commuter traffic caused by the end of the day rush hour and a Minnesota Twins baseball game.' Fortunately for those involved, there were multiple systems in place to communicate disaster information including a statewide Medical Resource Control Center (MRCC). The MRCC directs communications for the emergency medical service (EMS) agencies in the region and a web based system, which posts information about patient locations, destinations, number of beds available, and emergency department (ED) statuses. Minneapolis police, fire, EMS, hospitals, and other services also have detailed incident plans and regularly perform drills for disaster scenarios. ${ }^{9}$
Through these detailed plans and routine practice scenarios, communication pathways between responders were established and those who respond were knowledgeable about how to react in disaster situations. When an "Alert Orange" is issued, Minneapolis hospitals retain on duty personnel, have all available ED staff come to the hospital, and create a command center to deal with the increased number of patients who will be transported to the hospital in the wake of a disaster. ${ }^{9}$ By using the established MRCC, in person runners, and radios, communication delays caused by busy cell phones and hospital switchboards are minimized and efficient communication can continue between hospitals about patient locations.' Just like in the ED, additional laboratory staff is called in for the transfusion service and the laboratory has an extensive plan to deal with internal and external disasters. The transfusion service is responsible for assessing the blood supply, contacting the medical director, communicating with the blood center, and having a massive transfusion policy. Measuring how much time is required to receive blood products from the blood center to the trauma center is also included. By creating communication plans, including the blood bank in planning, and practicing disaster scenarios with routine drills, Minneapolis is better prepared to respond when disaster strikes.?

\section{San Francisco, California}

The city of San Francisco, California experienced a manmade disaster on July 6, 2013, when Asiana Airlines flight 214 crashed while preparing to land. ${ }^{10}$ One hundred ninety-two people were injured, the most common injury being spinal fracture. ${ }^{10}$ The hospital had a massive transfusion protocol in place and used one hundred seventeen blood products within the first fortyeight hours. Since the average number of products used per patient was 0.7 , from this study, it was estimated that in a mass casualty incident, trauma centers should expect to use one unit of blood per patient. ${ }^{10}$ Using this statistic, it is imperative for trauma centers to gauge their initial blood supply with reports of injured patients who would be transported to their hospital by comparing the inventory numbers to the number of incoming patients.

\section{$\underline{\text { Israel }}$}

Because a mass casualty incident can cause overwhelming workloads and the need for blood can be urgent, Hadassah University Hospital in Jerusalem, Israel evaluated suicide-bombing victims that were taken to 


\section{FOCUS: DISASTER PREPAREDNESS IN THE BLOOD BANK}

this hospital between October 2000 and December 2005. The goal of this study was to learn the patterns of blood usage and plan for the necessary resources to maximize the effects of blood transfusions and survival of patients when blood stores become limited. ${ }^{11}$ When a mass casualty incident (MCI) occurs, supervisory staff recruit additional personnel and help mobilize extra workspace in the blood bank in order to perform specimen testing, check inventory levels, and the blood product inventory that may be ordered from the blood center. The hospital blood bank estimates the use of three units of blood per severely injured patient and two units per moderately injured patient. When disaster strikes, the blood bank sends a delegate along with a transfusion medicine physician to the ED to help ensure proper labeling and handling of blood bank specimens and coordinating transfusions. In order to prevent specimen and patient misidentification, each patient is given a temporary identification number, which is linked to his or her real name once identified. ${ }^{11}$

By analysis of 18 terrorist attacks that took place in Tel Aviv, Israel between 1997 and 2005, the Tel Aviv Sourasky Medical Center (TASMC) was able to predict how many units of blood might be used during an MCI based on the type and size of the event. When an MCI takes place, the blood bank recruits extra personnel, takes an inventory of the blood supply and other supplies, evaluates work priorities, and begins working on patient samples. By evaluating these variables, changes can be made to adapt to the size of the MCI. ${ }^{12}$ If more than twenty five patients are admitted during a disaster it was observed that greater than 300 red blood cell units are utilized and the blood bank workload drastically increases. The TASMC determined that by using their standard operating procedure, there was no shortage of blood and the blood was supplied efficiently. ${ }^{12}$ Estimates show that in a small MCI, one unit of red cells is used per patient, versus two per patient in a larger MCI. By using these estimates and the anticipated number of patients that will be brought to the hospital, an approximate number of required red cell units can be determined. ${ }^{12}$

\section{Boston, Massachusetts}

When the Boston Marathon bombings occurred on April 15, 2013, the Brigham and Woman's Hospital was quickly notified of the event and able to activate the Hospital Incident Command System. Patients who were in the ED for other reasons were moved to other areas of the hospital and the staff quickly preregistered the anticipated trauma victims. As patients arrived and were assigned the preadmitted names, it was determined that patient identification was difficult because each prechosen name was similar to the others. ${ }^{13}$ Staffing was sufficient, but the rapid influx of patients made it difficult for the staff to keep track of patient locations and enter patient orders into the computer. ${ }^{13}$ These two variables created a potentially dangerous situation that could have led to patient misidentification.

After the bombing, staff members of many different specialties provided feedback about challenges they experienced and made suggestions of how to better the processes. Research was then conducted on how other trauma centers handle these issues. A new naming system was established to eliminate the confusion and preprinted paperwork for preregistered, unidentified patients and to more easily keep track of names and orders. A new unit leader position was created to help monitor communications and track patient locations. Any extra personnel that present to help in the ED are now to be used to enter patient orders into the computer. In looking back at previous events and modeling plans after other successful trauma centers, a facility can correct their identified shortcomings and streamline processes into a more safe and efficient workflow. ${ }^{13}$

\section{Communication}

Communication during a disaster needs to occur between laboratory workers, management, doctors, nurses, first responders, blood centers, suppliers, and others. During a disaster, back up lines of communication need to be in place incase landlines, computers, cell phones, the Internet, and other means of contact fail. It is also important to have access to phone numbers, email addresses, and other contact information of the persons who should be contacted before, during, and after a disaster in each required department and agency as both paper and digital sources. ${ }^{3}$

In order to have a coordinated response to disasters, Los Angeles County has a comprehensive trauma system in place, which includes a Medical Alert Center (MAC). The MAC coordinates communication between police, fire, EMS, and hospitals to relay bed availability and triage patients to the many trauma centers. ${ }^{14}$ These types of systems will not only help disaster management run 


\section{FOCUS: DISASTER PREPAREDNESS IN THE BLOOD BANK}

more efficiently, but due to this magnitude of organization, patients are likely to experience better outcomes. Unfortunately, most states do not have a statewide trauma system. Funding was allocated to develop a nationwide trauma system infrastructure with the Trauma Care Systems Planning and Development Act of 1989; however, the funding was never adequate to actually create these systems. Other funds have been allotted to aid in trauma infrastructure, but instead of creating a communication system, the funds were prioritized to aid hospitals in biohazard response, decontamination, and supplies. ${ }^{14}$

Another valuable group that needs to be communicated with is the media. Besides getting important updates on safety and the current state of the disaster, the media can also assist in controlling the use of valuable staff and supply resources. Major disasters initiate the desire in human beings to help those in need, and one way to do that is by donating blood. The September 11, 2001 terrorist attack has been the only incident in the United States since 1975 that has required more than 100 units of blood in the first twenty-four hours. In New York City, 224 units of blood were used. Even though the events were devastating, they did not require the use of more blood than was already in existing inventories between local hospitals and blood centers. Consequently, the New York Blood Center received five thousand donations in the first twelve hours and a total of 475,000 donated units. While donating blood is often considered a noble thing to do in the time of crisis, it is counterproductive unless there is an actual need for blood. ${ }^{15}$ The media can help quell the public's urge to donate and communicate other ways in which the public can support those in need. ${ }^{15}$

Because blood is a valuable and irreplaceable resource, thorough planning for needs and usage, transportation, and acquisition are imperative. The AABB Interorganizational Task Force has provided guidelines for communication between hospitals, blood centers, and the Task Force. When a disaster occurs, the hospital transfusion service should take inventory of its blood supply and report those numbers and their expected needs to the blood collector. The blood collector should contact the Interorganizational Task Force within one hour of the event to relay not only the hospital needs, but the needs of the blood collector as well. Because this task force consists of multiple organizations, it can coordinate the shipping, distribution, and other needs for communications in an official capacity. ${ }^{2}$ Many different individuals, organizations, and the public are involved when a disaster occurs. Thorough and frequent communication is necessary for safety and a continuity of care. $^{2}$

\section{Practicing Disaster Management}

Once an Emergency Operations Plan (EOP) is created, education, assigning rolls, practicing, and review of the plan need to occur. By discussing the risks, explaining the staffing responsibilities, identifying the communication methods, and outlining the authority structure, the staff members can begin to understand their role and prepare for an emergency. ${ }^{3}$ The main question to ask about an EOP in an emergency scenario is "will it work?". The only way to find out, besides participating in a disaster, is to practice the plan. The drills need to fit budget constraints, allow the lab to continue to care for patients, and be realistic scenarios. Drills should be based on a frequency that permits enough time between the drills to update changes that effect the EOP like changes in staffing, equipment, and laboratory operations. ${ }^{3}$ After the completion of a disaster simulation, those involved should be debriefed about how successful the drill was, as well as how well the EOP anticipated needs and adequately covered the elements needed to respond to the disaster. In addition to successes, failures and areas that need improvement need to be included in the debriefing. Each area requiring improvement should be evaluated and the EOP updated to better prepare for potential disasters. Plans need to be reviewed at least annually or sooner if there are changes in the lab or organization. $^{3}$

\section{Summary}

Disaster planning and EOP implementation is a multistep and detail-oriented process. Plans should be generated to support a facility in case a disaster occurs, and these plans should encompass possible natural and manmade hazards a facility may experience. ${ }^{3}$ Through reviewing hypothetical events and researching past incidents, a facility can better postulate the necessary steps needed to develop a successful Emergency Operation Plan. ${ }^{3}$ A proper plan can be created by means of utilizing this research and using published guidelines. In emphasizing communication, staff education, and completing practice disaster drills, the plan can be reviewed and changed to formulate a more successful 
EOP. ${ }^{1}$ The goal of a proper disaster plan should be to assist staff in helping to keep those involved safe and increase the survival of those harmed. Every minute detail can never be planned for, but having a strong plan in place will help an organization navigate through an event that falls outside of their normal day to day operations.

\section{REFERENCES}

1. AABB. Technical Manual. $18^{\text {th }}$ ed. Bethesda (MD): AABB; 2014.

2. AABB. Disaster Operations Handbook. $2^{\text {nd }}$ ed. Bethesda (MD): AABB; 2008.

3. CLSI. Planning for Laboratory Operations During a Disaster; Approved Guideline. CLSI document GP-36A. Wayne (PA): Clinical and Laboratory Standards Institute;2014.

4. Doughty H, Glasgow S, Kristoffersen E. Mass casualty events: blood transfusion emergency preparedness across the continuum of care. Transfusion. 2016;56 Suppl 2:208.

5. McQuilten ZK, Mercer G, Phillips L, Luangwilai T, Brown R, Ozolins I, et al. A dynamic mathematical model of red blood cell clinical demand to assess the impact of prolonged blood shortages and transfusion restriction policies. Transfusion. 2014;54(10):2705-15.

6. Kamp C, Heiden M, Henseler O, Seitz R. Management of blood supplies during an influenza pandemic. Transfusion. 2010;50(1):231-9.

7. Galloway MJ, Jane G, Sudlow L, Trattles J, Watson J. A tabletop exercise to assess a hospital emergency blood management contingency plan in a simulated acute blood shortage. Transfus Med. 2008;18(5):302-7.
8. Nollet KE, Ohto H, Yasuda H, Hasegawa A. The great East Japan earthquake of March 11, 2011, from the vantage point of blood banking and transfusion medicine. Transfus Med Rev. 2013;27(1):29-35.

9. Gorlin JB, Hick JL. Minneapolis bridges falling down: emergency transfusion preparedness. Transfus Apher Sci. 2013;49(3):403-7.

10. Campion EM, Juillard C, Knudson MM, Dicker R, Cohen MJ, Mackersie R, et al. Reconsidering the Resources Needed for Multiple Casualty Events: Lessons Learned From the Crash of Asiana Airlines Flight 214. JAMA Surg. 2016;151(6):512-7.

11. Bala M, Kaufman T, Keidar A, Zelig O, Zamir G, MudhiOrenshat $S$, et al. Defining the need for blood and blood products transfusion following suicide bombing attacks on a civilian population: a level I single-centre experience. Injury. 2014; 45(1):50-5.

12. Soffer D, Klausner J, Bar-Zohar D, Szold O, Schulman CI, Halpern $\mathrm{P}$, et al. Usage of blood products in multiple-casualty incidents: the experience of a level I trauma center in Israel. Arch Surg. 2008;143(10):9; discussion 989.

13. Landman A, Teich JM, Pruitt P, Moore SE, Theriault J, Dorisca E, et al. The Boston Marathon Bombings Mass Casualty Incident: One Emergency Department's Information Systems Challenges and Opportunities. Ann Emerg Med. 2015;66(1):51-9.

14. Cryer HG, Hiatt JR. Trauma system: the backbone of disaster preparedness. J Trauma. 2009;67(2):11.

15. Aylwin CJ, Konig TC, Brennan NW, Shirley PJ, Davies G, Walsh MS, et al. Reduction in critical mortality in urban mass casualty incidents: analysis of triage, surge, and resource use after the London bombings on July 7, 2005. Lancet. 2006; 368(9554):2219-25. 